\title{
El Espíritu Santo en su índole trinitaria y esponsal según Guillermo de Saint Thierry
}

\section{The Holy Spirit in Its Trinitary and Espousal Nature according to St-Thierry}

\section{EVA REYES-GACITÚA}

Universidad Católica del Norte, Antofagasta, Chile

ereyesg@ucn.cl, ORCID: 0000-0002-5233-3785

\begin{abstract}
Resumen: El teólogo y místico Guillermo de Saint Thierry elabora un pensamiento pneumatológico Trinitario en cuyo centro se encuentra el dinamismo esponsal. Desde este lugar, se reflexionan las principales formulaciones del autor a partir de la Expositio super Cantica canticorum: primero, situando en la cima de su comprensión al amor como primicia del Espíritu; segundo, del progreso de la belleza a la fuente de todo bien, refiriéndose a la reciprocidad de los amados y finalmente, de los dos a un solo Espíritu. A partir de estos ejes se intenta comprender y analizar la Unitas spiritus en cuanto acontecimiento económico en la vida del creyente, desde el cual nuestro autor articula que el Espíritu Santo hace posible la unidad de Dios Padre e Hijo, como la de Dios y la humanidad.
\end{abstract}

Palabras clave: Trinidad; Cantar de los Cantares; Esposo-esposa; Amado; Unitas spiritus.

Abstract: The theologian and mysticist William of St-Thierry elaborates a pneumatological thought centering around espousal dynamism. From this place, the author's main formulations are reflected from Expositio super Cantica canticorum: First, placing love as a primacy of the Spirit on top of its understanding; second, from the progress of beauty to the source of every good, referring to lovers' reciprocity and, finally, from the two to only one Spirit. From these axes, we intend to understand and analyze Unitas spiritus, as an economic event in the life of a believer, from whom our author articulates that the Holy Spirit makes possible the unity of Father God and Son, as well as that of God and mankind.

Keywords: Trinity; The Song of Songs; Husband and wife; Loved one; Unitas spiritus

Guillermo de Saint Thierry, místico y filósofo con el genio y capacidad de los grandes maestros ${ }^{1}$. Reformador de la vida monástica, dotado de una inteligencia viva y denominado por Benedicto XVI el "Cantor del amor, de la caridad". Su nacimiento se ubica en 1085, Lieja ${ }^{3}$. De familia noble, formado en las escuelas más famosas de su tiempo. Ingresó junto a su hermano Simón al monasterio de San Nicasio de Reims, donde llegó a ser abad de Saint Thierry. Más tarde, al encontrarse con Bernardo, hace realidad un deseo que -hasta entonces- no le deja tranquilo: renuncia a la abadía para compartir la pobreza y servir como un simple monje del Cister ${ }^{4}$. No obstante, el abad

\footnotetext{
Cf. Merton, "Blessed William of Saint-Thierry", 3.

Benedicto XVI, Audiencia General.

Cf. La fecha de nacimiento es controversial. De La Torre, Guillermo de Saint-Thierry, 93.

Cf. De La Torre, Guillermo de Saint-Thierry, 96.
} 
de Clairvaux ironiza respecto aquella certeza, tratándola de ilusión ${ }^{5}$. Ahora bien, el período de 1135 en adelante, como monje en Signy atestigua lo contrario; su vida y obra transcurren con el compromiso del pedagogo, el teólogo y el místico hasta su muerte en 1148. Justamente allí, nuestro autor redacta las obras de espiritualidad más importantes para la historia de la teología monástica.

Sus logros teológicos son relevantes, se destaca su actuación contra Abelardo, aunque al comienzo de su redescubrimiento se le clasificó como demasiado tradicionalista. Su contribución al trinitarismo medieval vale sobre todo para su teología mística, en cuanto se opuso a los dialécticos de la así llamada escolástica temprana. Por otra parte, en cuanto místico y espiritual se sitúa en armonía con poetas y pensadores que ven en el amor una fuerza vital ${ }^{6}$, toma distancia de la persistente oposición de las nociones formales, donde conocimiento y amor son irreductibles ${ }^{7}$. Desde este lugar emerge la Expositio super Cantica canticorum que será el punto de partida para este análisis. Para Guillermo el Cántico es una obra de teatro, representado a través de personajes y actos. Este comienza con la presencia del Esposo que obsequia prendas de amor a su esposa y luego desaparece de su vista. De este modo, el alma-esposa, después de haberle gustado, suspira anhelante por el encuentro definitivo. A partir de este movimiento de presencia y ausencia, el alma comprende que es Dios quien viene a amarse en ella.

El objetivo de este estudio estriba en comprender y examinar la presencia del Espíritu Santo en la dinámica esponsal. Para ello el procedimiento metódico se abre a una lectura complexiva de la obra guillerminiana, ordenando la articulación central de su pensamiento a partir de tres ejes: primero; el amor como primicia del Espíritu. Segundo, del progreso de la belleza a la fuente de todo bien. Tercero, de los dos a un solo Espíritu. Finalmente, la conclusión destacará los elementos fundantes de esta indagación.

\section{El amor como primicia del Espíritu}

Guillermo subraya que el amor es el núcleo de la vida del creyente. Esto quiere decir que el hombre ha sido creado a imagen de Dios para contemplarle y gozarle. De este modo lo confirma el Cantar: "Belleza del Bien supremo, que arrebatas con el deseo de poseerte a toda alma racional, que tiende tanto más ardientemente hacia ti..." (CCEE, 23). Se trata de un amor viviente, luminoso y libre que permite gozar del prójimo y de sí mismo, en cuanto ese gozo ha de ser en "Dios mismo" (CCEE, 24).

\footnotetext{
Cf. De La Torre, Guillermo de Saint-Thierry, 99.

Cf. Ruh, Geschichte der abendländischen Mystik, 277-278.

Cf. Rousselot, El problema del amor, 185.
} 
Para la comprensión guillerminiana esta es la gracia que desciende a su nivel y lo levanta hasta ella, transformando la grandeza de su majestad en afectos familiares y amicales. Por esta razón, el Señor se dirige a la esposa y le habla a su corazón diciendo: "Yo soy tu salvación", citando el Salmo 34,3. Ella ha de darse cuenta que Él es su ayuda y sostén. De ahí la exigencia "Habla, pues, Señor...habla para que oiga, manifiéstate por tu soplo para que perciba, dale para que posea, para que sus entrañas te bendigan..." (CCEE, 25). Ahora bien, si el amor no existe, de esta conversación surgirá y si existe, lo acrecentará. De este modo la sierva cautiva pasará al abrazo del vencedor para un amor eterno y una unión indisoluble (cf. CCEE, 25). ¿Qué ha querido subrayar nuestro autor? Sino indicar que mediante esta dinámica se avanza hacia una experiencia de intimidad cada vez mayor entre el hombre y Dios. Es el coloquio de amor entre el Esposo y la esposa, donde el Espíritu Santo ilumina y vivifica el deseo en amor de delectación (cf. CCEE, 26), en la línea agustiniana de efficacia connexionis.

Ahora bien, ¿qué denota el vocablo amor? Para el abad de Saint Thierry se trata del amor de Dios, del amor con que Dios es amado o del Amor que es Dios mismo (cf. CCEE, 27). Se le puede llamar amor, caridad o dilección. "Amor" indica la tierna inclinación del amante que tiende hacia su objeto y lo abraza, es también "caridad", cierto afecto espiritual, o el gozo de la posesión y "dilección", comprendida como el apetito natural que despierta un objeto deleitable (cf. CCEE, 27). Todo esto en el amor del Esposo y la esposa, es obra de un único y mismo Espíritu (cf. CCEE, 27). En efecto, se trata de un amor que abraza, sostiene y completa al ser humano.

A partir de este coloquio la fisonomía del hombre comienza a renovarse cada vez más a imagen de Dios por la acción del Espíritu Santo. Entonces según el abad de Saint Thierry adviene la gracia "que se apodera de la razón, del espíritu, de la vida, las costumbres y aun de la complexión corporal" (CCEE, 36), para actuar y transformar todo en un afecto de piedad; es decir, todo se inclina en una "imagen de caridad, en un rostro que busca a Dios" (CCEE, 36); a semejanza de Abraham subiendo el Moria en Gn 22, 1-18. Este es el momento en el cual se da lugar a la condescendencia divina en términos de Jn 14, 23: "Si alguno me ama, guardará mi palabra, y mi Padre le amará; y vendremos a él y haremos morada en él”. Para nuestro autor, Dios se da a conocer en una cierta medida, ya que el hombre no puede ver su rostro y seguir viviendo. Por ello, coloca en su corazón de quien le ama y confía "una cierta imagen" de su conocimiento, que no es producto de su imaginación, sino se trata de un piadoso afecto que el hombre puede recibir (cf. CCEE, 37). Afección que confiere fuerza y estabilidad a la intimidad de la persona y se ofrece como la extraordinaria energía actuante del Espíritu Santo ${ }^{8}$. De este modo, -en esta vida- para nuestro autor, Dios se deja alcanzar, por un piadoso afecto, de lo cual es capaz la naturaleza humana plasmada como sapere Deum. Estas son las primicias del Espíritu, la dote del tálamo nupcial

8 Cf. De La Torre, Guillermo de Saint-Thierry, 161. 
Non enim pedibus sed affectibus curris 9 . San Ambrosio y san Agustín han dicho que el alma se mueve por los buenos sentimientos y se aproxima así a Dios. De este modo, la esposa experimenta la llegada del Esposo y le encuentra cuando percibe que Él opera en ella. Esta es la inteligencia propia del amoris intellectus; en cuanto en el ejercicio de la contemplación de la divinidad, la naturaleza humana puede elevarse sobre la capacidad del hombre ${ }^{10}$. Análogamente, Guillermo afirma que la perfecta similitud del hombre para con Dios se advierte, en términos psicológicos, como la incapacidad de querer otra cosa de aquello que Dios quiere ${ }^{11}$. En definitiva, la búsqueda de Dios hace que el ser humano se vuelva a su propia imagen y semejanza de Dios -que porta dentro de sí- las huellas de la Trinidad ${ }^{12}$. De este modo, el centro es la experiencia del encuentro. Expresión teológica-mística percibida como fondo del alma, ya que el centro es la estancia más interior donde habita Dios mismo ${ }^{13}$.

En síntesis, para la comprensión de nuestro autor, el amor de Dios ha sido derramado en nuestros corazones y la esposa se comienza a conocer, como antes fue conocida nosce te ipsum. Este conocimiento permite al ser humano progresar hacia la perfecta semejanza con Él, fuente de todo bien.

\section{Del progreso de la belleza a la fuente de todo bien}

La participación en Dios se encuentra relacionada al bien y la belleza, por esta razón la esposa es amada y el Esposo reconoce en repetidas ocasiones su belleza: "Oh, la más bella de las mujeres, oh amiga mía"14. Para Guillermo esta frase denota las lisonjas que provienen del afecto, traducidos en vocablos de amor y de alabanza. "La más bella, dice, entre las mujeres". Bella, porque es hermosa, por haber sido formada así (cf. CCEE, 63), pues es Dios quien infunde su gracia en el ser humano, mediante el Espíritu Santo, de modo que el hombre queda iluminado por su resplandor: "ciertamente, no se puede dudar que, para amarte de ese modo, ella ha tenido que ser iluminada alguna vez por el resplandor de tu rostro..." (CCEE, 54). A partir del resplandor del Rostro divino, bajo el impulso de la gracia, la naturaleza del hombre se restaura. Pues "en el momento en que la gracia la visita, el espíritu adherido a Dios, la carne al espíritu, le dan un rostro de paloma, radiante de humildad, de castidad, del encanto de la santa simplicidad" (CCEE, 70). De este modo, la belleza de la es-

\footnotetext{
Cf. CCEE, 155. Citando nota a pie de página 507.

Cf. Como, Ignis Amoris Dei, 85.

Cf. Malevez, "La doctrine de l'image", 189.

Cf. Pfeifer, "Amplexus oder Unitas spiritus?", 343.

Cf. Patt, El concepto teológico-místico, 60.

Saint-Thierry, Expositio altera super Cantica Canticorum (PL 180, 493C): Sponsus vero: O pulchra inter mulieres, o amica mea.
} 
posa es participación en la belleza del Amado ${ }^{15}$, "en cuanto a ti, que tiendes hacia la belleza para llegar a ser bella con su belleza...” (CCEE, 110). Reminiscencia del texto de Sab 1,1: "amad la justicia, los que juzgáis la tierra, pensad rectamente del Señor y con sencillez de corazón buscadle”.

En efecto, el Esposo la encuentra bella en cuanto se ha acercado a ella: "He aquí que eres bella, amada mía; he aquí que eres bella"16. A partir de la expresión "He aquí", Guillermo permite diferenciar dos lugares; por una parte, la esposa es bella en cuanto experimenta un sentimiento piadoso, es decir, un estado de unión tranquila e intensa con Dios. Entonces se hace bella. Por otra parte, esta belleza es admirada por el mismo Esposo, reconociéndola como "belleza de la perfección" por ser imagen de Dios (cf. CCEE, 101). A partir de este coloquio Guillermo comprende la meta del hombre, el cual ha sido creado a imagen de Dios, para que, recordándolo piadosamente, pueda conocerlo y, conociéndolo humildemente, llegue a amarlo; $y$, amándolo con ardor y sabiduría, goce de su experiencia, realizando así su definición de animal racional: esto es temer a Dios y observar sus leyes. Por consiguiente, esta es la suma expresión en el pensamiento guillerminiano que constituye a todo el hombre (cf. CCEE, 101), donde tres vocablos son indicativos de una ruta: memoria, intellectus y amor.

Para la esposa, recordar al Esposo es buscarlo en la simplicidad del corazón; conocerlo es sentir algo de Él en la bondad; amarlo es adherirse a Él, poseerlo en la alegría, identificarse con Él ${ }^{17}$.

Según nuestro autor, la repetición de las palabras del Esposo: "He aquí que eres bella, amada mía; he aquí que eres bella" confirma lo expresado, señala la afirmación del progreso de la belleza. Quiere decir que la esposa es hermosa en sus obras, así también en sus disposiciones íntimas. Por ello es bella: por su hermosura, por sus colores. Esta es la razón de los vocablos sugeridos, "purifica para el Señor su memoria, hace humilde su inteligencia y se adhiere a Él por el amor" (cf. CCEE, 103). Expresión que denota la reciprocidad del amor y el lugar que ocupa el Espíritu, formulada en Expositio super Epistolam ad Romanos:

quieres, pues, esto y vehementemente lo quieres, que por tu Espíritu, tu amor, nos amas en ti $y$ te amas de nosotros y en nosotros. No es, pues, para nosotros y por nosotros, que esta preciosa sustancia, por la que te amamos, sino por tu Espíritu Santo, que nos das. Dánoslo,

15 Cf. Como, Ignis Amoris Dei, 208.

16 Saint-Thierry, Expositio altera super Cantica Canticorum (PL 180, 504A): In hoc ergo statu seu habitu mentis sponsus sponsam inueniens: Ecce, inquit, tu pulchra es, amica mea, ecce tu pulchra.

17 Saint-Thierry, Expositio altera super Cantica Canticorum (PL 180, 503D-504A): Sponsae namque memoria de sponso est in simplicitate cordis quaerere sponsum; intellectus sentire de eo in bonitate; amor ipsi affici, ipso frui, esse sicut ipse est. 


\section{EVA REYES-GACITÚA}

pues, para que habite en nosotros, oh Dios, y te amemos, moviéndonos y ascendiendo en tu amor, iluminando y excitando ${ }^{18}$.

En fin, amor y belleza se correlacionan. Luego, habiendo recibido del Esposo esta alabanza, la esposa le retribuye diciendo: “QQué hermoso eres, Amado mío, qué apuesto!”. Se intercambian el mismo elogio, ipsum est mutuum eorum colloquium. El Esposo es reconocido "apuesto, hermoso y amado" (CCEE, 104). Para nuestro autor los esposos se introducen en una amistad y mutuamente se complacen. Estamos situados ante el preludio del gozo de la unión consumada:

Y así, mientras continúa el intercambio de amor, mientras se progresa hasta la medida de la perfección concedida por Dios, ya sea sin orden o paso por paso, el Esposo y la esposa conversan, la esposa con el afecto de su devoción, el Esposo, en cambio, por el efecto de la gracia operante ${ }^{19}$.

Para la esposa, hablar al Esposo es mostrarse a sus ojos tal cual es; para el Esposo, conversar con ella es ordenarla y disponerla para conocerlo a partir de ella misma (cf. CCEE, 104). ¿Cuál es el sentido de esta frase? Según Guillermo ordinare uel disponere implica que el Amado se encuentra en ella y obra en ella. Este es un punto de vista dogmático que apunta a una lectura económica, en su orden salvífico. Reminiscencia de Jn 10,30: el Padre y yo somos uno.

En el pensamiento guillerminiano es radical esta expresión y lo confirma la frase: "Ella comienza a conocerse y a descubrir en sí misma lo que buscaba" (CCEE, 104). A medida que avanza comprenderá todo lo que habita en ella es digno de alabanza por cuanto procede de Él, fuente de todo bien y principio de toda belleza (cf. CCEE, 105). Las mutuas lisonjas entre los esposos es producto de la semejanza de su belleza. Esto provoca el goce, y el uno se encuentra en el otro: mutua ad inuicem sponsi sponsae que fruitio ${ }^{20}$. En este sentido se ocasiona la siguiente concordancia: "no hay semejanza posible fuera del goce que le está unido, ni goce sin la semejanza que lo provoca" (CCEE, 105). Guillermo subraya que en este vértice se encuentra la idea de "conformación": "Cuando con más ardor el humilde amor se inclina hacia Él, se va conformando al objeto de su inclinación” (CCEE, 105). Con esta expresión nuestro

18 Saint-Thierry, Expositio in epistolam ad Romanos (PL 180, 592 A-B): Vis enim hoc, et vehementer vis ut per Spiritum tuum, amorem tuum, ames nos in te, et ames te de nobis et in nobis. Non enim est nobis a nobis tam pretiosa haec substantia qua te diligimus, sed a Spiritu sancto tuo quem das nobis. Da ergo eum nobis, et in nobis habitans, o Deus, ama te de nobis, movendo nos et accendendo ad amorem tuum, illuminando et excitando.

19 Saint-Thierry, Expositio altera super Cantica Canticorum (PL 180, 504D): Sicque dum negotium amoris agitur, dum ad mensuram donandae a Deo perfectionis passim uel gradatim proficitur, sponsus et sponsa ad inuicem loquuntur: sponsa deuotionis affectu, sponsus uero gratiae operantis effectu.

20 Saint-Thierry, Expositio altera super Cantica Canticorum (PL 180, 505B): Hanc autem reciprocam ad alterutrum gratiam, ipsa de qua agimus, facit mutua pulchritudinis similitudo, mutua ad inuicem sponsi sponsae que fruitio. 
abad comprende que el hombre ha sido modelado a imagen de su Hacedor y, por tanto, el hombre se adhiere a Dios y

se hace con Él un solo espíritu, bello en el Bello, bueno en el Bueno, y esto a su modo, según la fuerza de su fe, la luz de su inteligencia y la magnitud de su amor, llegando a ser en Dios, por gracia, lo que Él es por naturaleza ${ }^{21}$.

Efectivamente, nos encontramos situados ante una teología ascensional, puesto que el hombre para percibir algo de Dios, contrae tal semejanza en virtud de una dulce experiencia, "semejanza conforme, a la vez, a la naturaleza de la imagen percibida y del amor que la percibe" (CCEE, 106). Así como el que percibe se transforma en lo percibido. A pesar que esta similitud y semejanza de Dios ha sido rota por el pecado original, Guillermo destaca que no ha sido eliminada, se restablece por gracia a través y nuevamente por medio del Espíritu Santo ${ }^{22}$. En definitiva, la gracia arraiga al ser humano por el affectus en el bien, de este modo el hombre permanece unido a Dios, pese a todos los cambios de su vida ${ }^{23}$.

Finalmente, nuestro autor ha sabido resaltar la unión admirable entre el Creador y la creatura. El intercambio de amor y belleza entre los amados conforma al hombre a su Hacedor para llegar al goce de la posesión, señalando la paradójica comprensión de los dos a un solo Espíritu.

\section{De los dos a un solo Espíritu}

En el siguiente párrafo Guillermo subraya las acciones que provoca el beso de los desposorios, todos son verbos que se encuentran en movimiento: ofrece, imprime, produce, inunda, infunde, los cuales permiten recordar la presencia de la gracia creada:

Este es el beso que ofrece e imprime a su esposa, el alma fiel, cuando produce en ella un gozo personal y exclusivo, que nace del recuerdo de los beneficios comunes y la inunda con la gracia de su amor, mientras atrae el espíritu de ella hacia Él y le infunde el suyo, para hacer de los dos un solo espíritu².

21 Saint-Thierry, Expositio altera super Cantica Canticorum (PL 180, 505C): [...] hoc est cum Deo unus spiritus, pulcher in pulchro, bonus in bono; id que suo modo secundum uirtutem fidei, et lumen intellectus, et mensuram amoris, exsistens in Deo per gratiam, quod ille est per naturam.

22 Cf. Ruh, Geschichte der abendländischen Mystik, 287.

23 Cf. Meis, El enigma del hombre, 67.

24 Saint-Thierry, Expositio altera super Cantica Canticorum (PL 180, 483C): Ipsum etiam osculum fideli animae sponsae suae porrigit et imprimit, cum de memoria communium bonorum, priuatum ei et proprium commendans gaudium, gratiam ei sui amoris infundit, spiritum eius sibi adtrahens et suum infundens ei, ut inuicem unus spiritus sint. 


\section{EVA REYES-GACITÚA}

Según nuestro autor, este beso tiene relación con la experiencia mística cuya meta es la "unidad de los espíritus". Deviene mediante un proceso por el cual el alma recuerda los beneficios obtenidos y comprende que es amada con un amor de exclusividad. Este amor se inflama y se funde en $\operatorname{Dios}^{25}$, claramente reminiscencia de 1 Cor 6,17: "más el que se une al Señor, se hace un sólo espíritu con él". Para nuestro autor en el beso se encuentra representado el Espíritu Santo, como lugar de encuentro del conocimiento y el amor ${ }^{26}$. Por ello el Espíritu Santo es la unidad del Padre y del Hijo, su amor recíproco, su beso y su abrazo ${ }^{27}$. Empero, no se trata de cualquier conocimiento de Dios, sino de una percepción más íntima, que converge en un conocimiento afectuoso especial entre el amor y la intelección ${ }^{28}$. Y así, como Cristo concede ese beso a la esposa, nosotros seremos incorporados a Cristo por su encarnación y pasión, haciéndonos partícipes de esa unidad ${ }^{29}$. De aquí deriva una sólida comprensión cristológica y pneumatológica. A saber, la esponsalidad se comprende en cuanto experiencia humana genuina, donde el uno no se encuentra solo frente al otro, sino existe en el otro. Es la llamada in-existencia que implica ir más allá de los dos, hacia el fruto. La que posibilita al Padre ser Padre y al Hijo ser Hijo, siendo atestiguada por el misterio de la unión hipostática en Cristo, declarada en Nicea 325. La teología edifica esta unidad en el Espíritu Santo, nexo de unión entre el Padre y el Hijo, fruto del amor en una única espiración (II Concilio de Lyon 1274). La cual ha sido posteriormente desarrollada a lo largo de la historia del Magisterio a partir de sus afirmaciones conciliares.

El Cantar camina hacia la unidad de los amados y el lecho es el lugar de la posesión, por ello la esposa afirma: "Nuestro pequeño lecho está cubierto de flores". Para el abad de Saint Thierry el lecho es la conciencia apacible; el gozo, en ella, del Espíritu Santo, que es en su misma fuente "la inagotable fruición de la verdad" (CCEE, 107). Allí, en efecto, se realiza la unión admirable entre el hombre y Dios, dada en "mutua fruición de la suavidad", en "alegría incomprensible" e "inimaginable aun para aquel que la experimenta". Es el nexo entre el espíritu creado y el increado (cf. CCEE, 107). El Cantar los llama Esposo y esposa, cuya unión es expresada en términos de "dulcedo" y "suauitatis" (CCEE, 107). En definitiva es:

la unidad del Padre y del Hijo, su beso mutuo, su abrazo, su amor, su bondad y todo lo que, en esta unidad infinitamente simple, es común a ambos. Todo esto es el Espíritu Santo, Dios, caridad, donante y don al mismo tiempo ${ }^{30}$.

25 Cf. CCEE, 50. Citando nota a pie de página 101.

26 Cf. Malevez, "La doctrine de l'image", 199.

27 Cf. Sander, "Glaube als Gehen", 419.

28 Cf. Rousselot, El problema del amor, 182.

29 Cf. Elder, "The Christology of William of Saint Thierry", 110-111.

30 Saint-Thierry, Expositio altera super Cantica Canticorum (PL 180, 506C): unitas Patris et Filii Dei, ipsum eorum osculum, ipse amplexus, ipse amor, ipsa bonitas, et quicquid in unitate illa simplicissima commune 
Dulcedo comporta para algunos autores: bondad, afección, amor ${ }^{31}$. No obstante, dulcedo et suauitatis se encuentran relacionados ${ }^{32}$. En Guillermo, ambos vocablos destacan la unión del Padre y del Hijo ${ }^{33}$. El In Canticum nos lo recuerda, pues en el lecho se intercambia el abrazo y el beso:

y como los amantes, en sus besos, por un mutuo y suave intercambio, transfunden uno en el otro sus almas, así el espíritu creado se derrama enteramente en el espíritu que lo crea por esta misma efusión; a su vez, el Espíritu creador se infunde según quiere y el hombre se hace con Dios un solo espíritu ${ }^{34}$.

Aquí se encuentra el punto culminante de una sólida teología trinitaria en Guillermo, por cuanto comprende que el Amor mismo es el Espíritu Santo, el cual procede del Padre y del Hijo, y con quien es uno (cf. CCEE, 112). Esto quiere decir, que el espíritu del hombre se encuentra estrechamente unido a Él, lo cual es expresado en la siguiente concordancia: "el espíritu al Espíritu, el amor al Amor, el amor humano se vuelve en cierta manera divino" (CCEE, 112). Sin embargo, viene una cuidadosa advertencia: cuando el hombre ama a Dios, ciertamente él es el operario, pero es Dios quien obra la 'gracia de Dios' con él. Reminiscencia de 1 Cor. 15,10: "Por la gracia de Dios, soy lo que soy... aunque no he sido yo, sino la gracia de Dios, que me acompaña".

Según K. Sander, cuando el abad de Saint-Thierry usa la expresión Unitas spiritus, denota en ella, un carácter de ayuda para expresar lo que siente y al mismo tiempo le otorga valor a la precisión; tanto en la formulación teológica de los pensamientos como en lo lingüístico. Este es el sentido notable cuando Guillermo comenta la Expositio y afirma: et fiat mutua uisio, mutuus amplexus, mutuum gaudium, unus spiritus $^{35}$. Es el amor del Padre y del Hijo, su unidad y su dulzura, el beso y el abrazo, la expresión de esta unidad ${ }^{36}$. M. Davy pregunta si la caridad es ella misma -ontológicamente- el Espíritu Santo. Ciertas afirmaciones de Guillermo irían por esta línea de comprensión "el Espíritu Santo, Él mismo, es Dios caridad" ${ }^{37}$ : Idem tamen, idem plane Spiritus ${ }^{38}$.

est amborum; quod totum est Spiritus sanctus, Deus caritas, idem donans, idem et donum.

31 Cf. Niermayer, Mediae Latinitatis, 362.

32 Cf. Carpenterii, Glossarium mediae, 960.

33 Saint-Thierry, Expositio altera super Cantica Canticorum (PL 180, 506C): [...] dulcedo et suauitas coniunctionis illius, quae non est alia quam unitas Patris et Filii Dei...

34 Saint-Thierry, Expositio altera super Cantica Canticorum (PL 180, 506C): et sicut solet in amantium osculis, suaui quodam contactu mutuo sibi spiritus suos transfundentium, creatus spiritus in hoc ipsum creanti eum Spiritui totum se effundit; ipsi uero creator Spiritus se infundit, prout uult, et unus spiritus homo cum Deo efficitur.

35 Saint-Thierry, Expositio altera super Cantica Canticorum (PL 180, 530B).

36 Cf. Pfeifer, "Kann man Mystik erlernen?", 518 y 519.

37 Cf. Davy, Théologie et Mystique, 160.

38 Saint-Thierry, Expositio altera super Cantica Canticorum (PL 180, 520B). 


\section{EVA REYES-GACITÚA}

Ahora bien, el acontecimiento de la inhabitación de Dios en el alma humana ha sido expresada a través del éxtasis o transitus, también comprendida como amplexus de los esposos, en cuanto supra hominem est ${ }^{39}$. Para Guillermo la propia personalidad del Espíritu Santo hace posible la unidad y reciprocidad de Dios Padre e Hijo, por una parte, y de Dios y el hombre, por otra. Esta idea la encuentra en una doble tradición, en la dogmática que proviene de san Agustín y la mística del Cantar que provine de Orígenes ${ }^{40}$.

Para A. Montanari en el simbolismo del amplexus ha sido relevante el influjo origeneano, sobre todo al leer "el abrazo" a la luz de Jn 13,25, interpretación que viene representada por Bernardo en el Sermón 51,5 en el Super Cantica ${ }^{41}$. Sin embargo, M. Pfeifer hace notar que tanto amplexus y osculum definen la unidad y la reciprocidad de Dios Padre e Hijo; pero no se refieren a ello en la misma frecuencia de unidad y reciprocidad de Dios y hombre ${ }^{42}$. Así, el Espíritu Santo llega a ser de manera humana para el hombre en relación a Dios, lo que es el Espíritu Santo para el Hijo en la consubstancial unidad para con el Padre ${ }^{43}$. Para nuestro autor el espíritu del hombre se encuentra unido al mismo Espíritu Santo. Guillermo comprende esta unión admirable como la relación del espíritu creado y el increado ${ }^{44}$.

La fórmula de Guillermo para ir al encuentro de Dios es llegar a ser un miembro del cuerpo de Cristo. Cristo justifica al creyente y lo incorpora a su cuerpo y nosotros nos encontramos por Cristo incorporados a Dios. Este pensamiento ha de ser entendido en forma trinitaria. No se trata de una mezcla de las personas divinas, sino es la expresión de que somos hijos y, por ende, somos incorporados a Dios. En este sentido, Guillermo desarrolla en la parte central de sus escritos místicos y exegéticos la unión mística como conclusión del ascenso espiritual en el amplexus del hombre y $\operatorname{Dios}^{45}$.

Aunque Guillermo insiste en la distancia que separa la condición humana de la eterna, en el abrazo, que comienza en esta vida, se encuentra el inicio de lo que llegará a ser en perfección. Este abrazo es el Espíritu Santo, es la comunión, caridad, amistad y abrazo del Padre y del Hijo ${ }^{46}$. Esta expresión ha sido magistralmente subrayada en Epistola ad Fratres de Monte Dei:

\footnotetext{
39 Cf. Ruh, "Die Hoheliederklärungen", 24.

40 Cf. Pfeifer, "Amplexus oder Unitas spiritus?”, 346.

41 Cf. Montanari, "Simbolismo", 262.

42 Cf. Pfeifer, "Amplexus oder Unitas spiritus?”, 341-342.

43 Cf. Pfeifer, "Kann man Mystik erlernen?", 519.

44 Saint-Thierry, Expositio altera super Cantica Canticorum (PL 180, 506B): In hoc siquidem fit coniunctio illa mirabilis, et mutua fruitio suauitatis, gaudiique incomprehensibilis, incogitabilis illis etiam in quibus fit, hominis ad Deum, creati spiritus ad increatum.

45 Cf. Sander, "Glaube als Gehen", 418-419.

46 Cf. Montanari, "Simbolismo", 260.
} 
esta es, de la cual se han dicho muchas cosas, tanto propias como semejantes, sino también se ha buscado la "unidad de espíritu": que el hombre se haga una cosa con Dios, un espíritu, no tanto por querer ser algo, sino por expresión de unidad. Cosa distinta es, no querer ser fuerte. Esta "unidad de espíritu" se lleva a cabo en el hombre por influencia del Espíritu Santo, ya que Él es el amor de Dios. Este amor eterno es el que une al Padre con el Hijo, le da unidad en la verdad. Esto es lo que hace al hombre dirigirse a Dios a su manera, como en el abrazo del Padre y del Hijo representan la conciencia feliz. Con un modo inefable e impensable merece el hombre hacerse hombre de Dios, no Dios, pero lo que es Dios por naturaleza, sea el hombre por gracia ${ }^{47}$.

En sentido positivo quiere decir que se comprende como la radical "unidad de espíritu" entre el hombre y $\operatorname{Dios}^{48}$. Unidad que debe entenderse a modo de una metáfora, como el comienzo de una plenitud que solo nos la puede dar la vida futura ${ }^{49}$.

En suma, Unitas spiritus, esgrimida en el lenguaje guillerminiano nos sitúa en el centro mismo de la temática esponsal. Es el vértice de la experiencia espiritual del hombre, por la cual le comunica, por gracia, su participación en la vida íntima de la Trinidad misma. Esta unidad es la que permite a la esposa progresar hacia la plenitud y gustar de la perfección.

\section{Conclusión}

Desde este lugar, podemos concluir que el Espíritu fluye en el pensamiento de Guillermo y se presenta como nexo entre la dinámica de la esponsalidad. Nuestro abad ha comprendido, que entre Dios y el hombre se origina una relación fundamentalmente trinitaria. Ya lo deja entrever en esta obra, en cuanto ha percibido la unidad: Unitas spiritus, el quiasma entre los esposos, no como una mera relación de procedencia, sino de encuentro interpersonal en el amor. Nos encontramos situados en el lugar más evidente desde donde nuestro autor muestra de forma clara cuál ha

47 Saint-Thierry, Epistola ad fratres de Monte Dei (PL 184, 349AB): Haec est de qua jam aliquanta dicta sunt, in tantum proprie propria, ut non jam similitudo, sed unitas spiritus nominetur; cum fit homo unum cum Deo, unus spiritus, non tantum unitate unitate volendi idem, sed expressiore quadam unitate virtutis (sicut jam dictum est) aliud velle non valendi. Dicitur autem haec unitas espiritus, non tantum quia efficit eam, vel afficit ei spiritum hominis Spiritus sanctus, sed quia ipsa ipse est Spiritus sanctus Deus charitas: cum per eum qui est amor Patris et Filii, et unitas, et suavitas, et bonum, et osculum, et amplexus, et quidquid commune potest esse amborum in summa illa unitate veritatis, et veritate unitatis; hoc idem homini suo modo fit ad Deum, quod cum substantiali unitate Filio est ad Patrem, vel Patri ad Filium; cum in amplexu et osculo Patris el Filii mediam quodammodo se invenit beata conscientia; cum modo ineffabili inexcogitabilique fieri meretur homo Dei non Deus, sed tamen quod Deus est ex natura, homo ex gratia.

48 Cf. Conley, "The Eremitical Anthropology", 126.

49 Cf. Buchmüller, "Die geistliche Lehre", 233. 


\section{EVA REYES-GACITÚA}

sido su aporte a la reflexión de la Trinidad, refiriéndose al Espíritu como don del Padre y del Hijo.

Así la espera del Esposo se da entre un continuo fluctuar entre la presencia y la ausencia, la revelación y el ocultamiento. Guillermo ha sabido captar la profundidad de este dinamismo tensionante; que posibilita a la esposa mantenerse despierta, expectante hasta que llegue el día pleno. Guillermo ha elaborado una reflexión de alto alcance teológico, en cuanto la Unitas spiritus constituye el vértice de la semejanza del hombre con Dios, que en el dinamismo esponsal, se expresa como participación en el amor, en el cual Dios se ama a sí mismo; haciéndonos un solo espíritu con Dios.

\section{Bibliografía}

Benedicto XVI, Audiencia General, miércoles 2 de diciembre de 2009. Disponible en http://w2.vatican.va/content/benedict-xvi/es/audiences/2009/documents/hf_ben-xvi_ aud_20091202.html (accessed June 1, 2020).

Buchmüller, W., "Die geistliche Lehre des seligen Wilhelm von Saint-Thierry", Cistercienser Chronik 105 (1998) 233-253.

Carpenterii, D. P., Glossarium mediae et infimae Latinitatis (Parisiis: Excudebant Firmin Didot Fratres 1842) II.

Como, G., Ignis Amoris Dei. Lo Spirito Santo e la trasformazione dell'uomo nell'esperienza spirituale secondo Guglielmo di Saint-Thierry (Dissertatio Series Romana. Pontificio Seminario Lombardo di Roma 34; Roma: Pontificio Seminario Lombardo - Milano: Glossa 2001).

Conley, J.J., "The Eremitical Anthropology of William of St. Thierry", Cistercian Studies 25 (1990) 115-130.

Davy, M.-M., Théologie et Mystique de Guillaume de Saint-Thierry (Paris: Vrin 1954).

De La Torre, J.M., Guillermo de Saint Thierry: Un formador de creyentes (Madrid: Claretianas 1993).

Elder, E.R.. "The Christology of William of Saint Thierry", Recherches de théologie Ancienne et médiévale 58 (1991) 79-112.

Guillelmus, S. Theodorici (Saint-Thierry), Expositio altera super Cantica Canticorum (PL 180, 474-546).

Guillelmus, S. Theodorici (Saint-Thierry), Expositio in epistolam ad Romanos (PL 180, 547-694).

Guillelmus, S. Theodorici (Saint-Thierry), Epistola ad fratres de Monte Dei (PL 184, 307-364).

Guillermo de Saint-Thierry, Comentario al Cantar de los Cantares. Traducción del texto latino y de las notas de Roberto Thomas (trad. María Rosa Suárez) (Padres Cistercienses 6; Azul: Monasterio Trapense de Ntra. Sra. De los Ángeles - Buenos Aires: Claretianas 1979) (= CCEE).

Malevez, L., "La doctrine de l' image et de la connaissance mystique chez Guillaume de Saint-Thierry", Recherche de science religieuse 22 (1932) 178-205. 
Meis, A., El enigma del hombre. Según Guillermo de Saint-Thierry, a la luz del encuentro entre cultura griega y latina (Santiago: Pontificia Universidad Católica de Chile 2004).

Merton, T., "Blessed William of Saint-Thierry: Monk of Signy", Cistercian Studies Quarterly 35 (2000) 3-12.

Montanari, A., "Simbolismo ed esegesi nell' Expositio Super Cantica Canticorum di Guglielmo di Saint-Thierry", Rivista Cistercense 15 (1998) 247-294.

Niermayer, J.F., Mediae Latinitatis Lexicon Minus (Leiden: Brill 1960).

Patt, S., El concepto teológico-místico de "Fondo del alma" en la obra de Edith Stein (Colección teológica 120; Pamplona: EUNSA 2009).

Pfeifer, M., "Amplexus oder Unitas spiritus? Kai G. Sanders neue Studie zur Geist-Mystik Wilhelms von Saint-Thierry", Cistercienser Chronik 106 (1999) 341-350.

Pfeifer, M., "Kann man Mystik erlernen? Die problematik des geistlichen Fortschritts bei Zisterziensern des 12. und des 20. Jahrhunderts", Cistercienser Chronik 108 (2001) 515-532.

Rousselot, P., El problema del amor en la Edad Media (Madrid: Cristiandad 2004).

Ruh, K., "Die Hoheliederklärungen Bernhards von Clairvaux und Wilhelms von St. Thierry", "Minnichlichiu gotes erkennusse". Studien zur frühen abendländischen Mystiktradition. Heildeberger Mystiksymposion vom 16. Januar 1989 (ed. D. Schmidtke) (Mystik in Geschichte und Gegenwart. I. Christliche Mystik 7; Stuttgart - Bad Cannstaatt: Frommann-Holzboog 1990) 16-27.

Ruh, K., Geschichte der abendländischen Mystik. I. Die Grundlegung durch die Kirchenväter und die Mönchstheologie des 12. Jahrhunderts (München: Beck 1990).

Sander, K., "Glaube als Gehen. Ganzheitliche Gottesbegegnung nach Wilhelm von St. Thierry", Cistercienser Chronik 105 (1998) 413-420. 
